
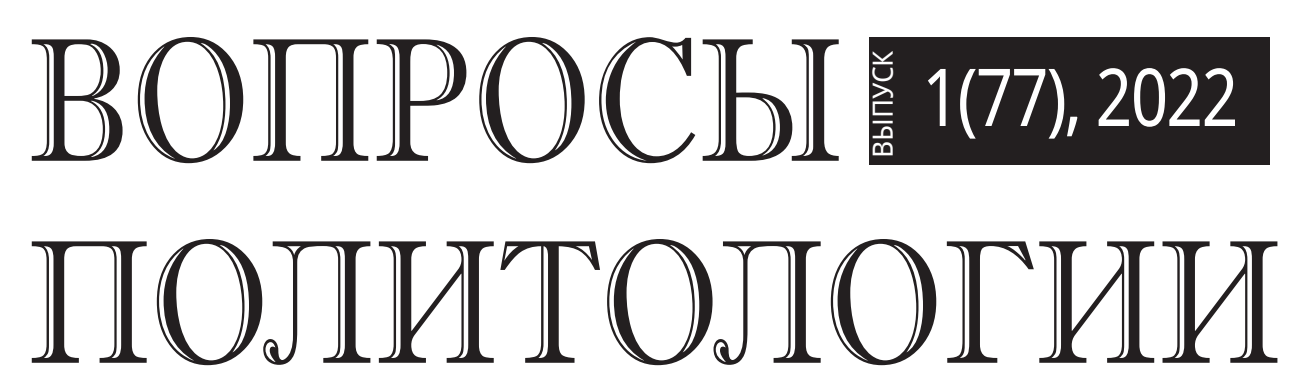

Научный журнал

Журнал «Вопросы политологии» включен

в Перечень рецензируемых научных изданий

ВАК при Министерстве науки и высшего образования РФ

по политическим наукам, в которых должны быть опубликованы основные научные результаты на соискание ученой степени кандидата наук, на соискание ученой степени доктора наук

Журнал включен в Перечень научных изданий рекомендованных ВАК Республики Узбекистан для публикации основных научных результатов диссертаций по политическим и философским наукам 
Председатель Редакционного Совета - ПЛАТОНОВ В.М.

к.ю.н., заведующий кафедрой политического анализа и управления РУДН,

Председатель Московской городской Думы (1994-2014 гг.)

\section{Редакционный Совет}

АВАЗОВ

Камиль Халлиевич

\section{АСТВАЦАТУРОВА}

Майя Арташесовна

БЛОХИН

Владимир Владимирович

БОЖАНОВ

Владимир Александрович

BАНКОВСКА

Биляна

\section{ВЕДРИН}

Оливье

ВЕЛИКАЯ

Наталия Михайловна

ГОНЧАРОВ

Пётр Константинович

ГРАЧЁВ

Михаил Николаевич

ДЭМБЭРЭЛ К.

\section{ДОНАЙ}

Лукаш

ЖИЛЬЦОВ

Сергей Сергеевич

КАРАДЖЕ

Татьяна Васильевна

КАССАЕ НЫГУСИЕ

В. МИКАЭЛЬ

КОВАЛЕНКО

Валерий Иванович

КОМЛЕВА

Валентина Вячеславовна

КРИВОКАПИЧ

Борис

МЕДВЕДЕВ

Николай Павлович

МИХАЙЛОВ

НАЗАРОВА

Елена Александровна

НАЗАРОВ

Александр Данилович

НАСИМОВА

Гульнара Орленбаевна

НИСНЕВИЧ

Юлий Анатольевич

ОРЛОВ

Игорь Борисович

ПАХРУТДИНОВ

Шукритдин Ильясович

ПЛЯЙС

Яков Андреевич

ПРЯХИН

Владимир Федорович

ПУСЬКО

Виталий Станиславович

РУБАН

Лариса Семёновна

\section{СЛИЗОВСКИЙ}

Дмитрий Егорович

СЫЗДЫКОВА

Жибек Сапарбековна

ХОПЁРСКАЯ

Лариса Львовна

ШАРКОВ

Феликс Изосимович

ЯН ФУЛИНЬ
Вячеслав Александрович

д.ф. (PhD) по полит. наукам, Региональный центр переподготовки и повышения квалификации работников народного образования Сурхандарьинской области (Узбекистан, г. Ташкент) д.П.н., профессор, Пятигорский государственный университет (Россия, г. Пятигорск)

д.и.н., профессор, РУДН (Россия, г. Москва)

д.и.н., профессор, Белорусский Национальный технический университет (Белоруссия, г. Минск)

профессор политологии и международных отношений

факультета философии Университета Святых Кирилла и Мефодия

(Македония, г. Скопье)

профессор, ректор «Континентального университета в Киеве»

(Франция, г. Париж)

д.П.Н., профессор, ИСПИ ФНИСЦ РАН, РГГУ (Россия, г. Москва)

д.с.н., профессор, Российский университет транспорта (МИИТ)

(Россия, г. Москва)

д.п.н., профессор, РГГУ (Россия, г. Москва)

доктор (PhD), Институт международных отношений АН Монголии (Монголия, г. Улан-Батор)

д.П.н., профессор, Университет им. Адама Мицкевича в Познани

(Польша, г. Познань)

д.п.н., профессор, Дипломатическая академия МИД РФ

(Россия, г. Москва)

д.ф.н., профессор, МПГУ (Россия, г. Москва)

д.и.н., профессор, РУДН (Россия, г. Москва)

д.ф.н., профессор, МГУ им. М.В. Ломоносова (Россия, г. Москва)

д.с.н., профессор, РАНХиГС при Президенте РФ (Россия, г. Москва)

д.ю.н., Унион-Никола Тесла университет (Сербия, г. Белград)

д.п.н., профессор, главный редактор журнала (Россия, г. Москва)

д.и.н., профессор, РАНХиГС при Президенте РФ (Россия, г. Москва)

д.с.н., профессор, МГИМО МИД России (Россия, г. Москва)

д.и.н., профессор, МАИ (Россия, г. Москва)

д.п.н., профессор, Казахский Национальный университел

им. Аль-Фараби (Казахстан, г. Алматы)

д.п.н., профессор, НИУ «Высшая школа экономики»

(Россия, г. Москва)

д.и.н., профессор, НИУ «Высшая школа экономики»

(Россия, г. Москва)

д.п.н., профессор, Институт переподготовки и повышения

квалификации руководителей и специалистов системы народного

образования имени А. Авлони (Узбекистан, г. Ташкент)

д.и.н., д.п.н., профессор, Финансовый университет при Правительстве РФ

(Россия, г. Москва)

д.п.н., профессор, РГГУ (Россия, г. Москва)

д.ф.н., профессор, ВА РВСН им. Петра Великого (Россия, г. Москва)

д.с.н., профессор, отдел исследования проблем международного сотрудничества Института социально-политических исследований ФНИСЦ РАН (Россия, г. Москва)

д.и.н., профессор, РУДН (Россия, г. Москва)

д.и.н., профессор, ИСАА МГУ им. М.В. Ломоносова

(Россия, г. Москва)

д.п.н., профессор, Киргизско-Российский славянский университет

(Киргизия, г. Бишкек)

д.с.Н., профессор, РАНХиГС при Президенте РФ (Россия, г. Москва)

проректор Хэйлунщзянского института иностранных языков (КНР, г. Харбин)

\section{Редакционная коллегия}

Главный редактор - МЕДВЕДЕВ Н.П., д.П.Н., профессор

Абрамова О.Д. (д.П.н.)

Насимова Г.О. (д.п.н.)

Кетцян Г.В. (к.П.н. - зам. гл. редактора)
Шкурина С.С. (к.П.н. - ответ. редактор)

\section{ЖУРНАЛ ВКЛЮЧЕН В ПЕРЕЧЕНЬ ВАК РФ}

\author{
УЧРЕЖДЕН \\ ООО «Издательство \\ «Наука сегодня»
}

Журнал зарегистрирован

Федеральной службой

по надзору в сфере массовых коммуникаций, связи и охраны культурного наследия

\section{Рег. № ПИ № ФС77-46176}

от 12 августа 2011 г.

Журнал издается ежемесячно

Журнал включен в базу РИНЦ

(Российский индекс

научного цитирования)

Включен в каталог

Ulrich's Periodicals Directory

Пятилетний импакт-фактор: 1,489.

Адрес редакции:

115598 , г. Москва, ул. Загорьевская д. 10, корп. 4, цокольный этаж, помещение I, комната 7-1, офис 4

Тел.: (910) 463-53-42

Интернет-ресурс:

www.voprospolitolog.ru

E-mail: voprospolitolog@yandex.ru

Мнение авторов может не совпадать с мнением редакции.

При перепечатке ссылка

на журнал обязательна.

Научные статьи, публикуемые в журнале подлежат обязательному рецензированию.

Ответственный редактор Шкурина С.С.

Перевод

Чернышова Е.В.

Компьютерная верстка Анциферова А.С.

Подписано в печать 27.01.2022

Формат 60×84/8. Объем 24,3 .

Печать офсетная

Тираж - 1000 экз.

(1-й завод - 500 экз.) Заказ № 000 .

Отпечатано в типографии ООО «Белый ветер»

115054, г. Москва, ул. Щипок, 28 Тел.: (495) 651-84-56 
ISSN 2225-8922 (print)

12 выпусков в год и

4 выпуска в год переводной (англ.) версии

Языки: русский, английский

http://voprospolitolog

Входит в перечень рецензируемых научных изданий ВАК РФ

Включен в каталог периодических изданий Ульрих

(Ulrich's Periodicals Directory: http://www.ulrichsweb.com)

Материалы журнала размещаются на платформе РИНЦ

Российской научной электронной библиотеки, Electronic Journals Library Cyberleninka

Подписной индекс издания в каталоге агентства Роспечать 70035

\section{Цели и тематика}

Журнал ВОПРОСЫ ПОЛИТОЛОГИИ - периодическое международное рецензируемое научное издание в области политических исследований. Журнал является международным как по составу редакционного совета и редколлегии, так и по авторам и тематике публикаций.

Научный журнал издается с 2011 года в издательстве «Наука сегодня». С 2016 года издается переводная (англ.) версия журнала. С момента своего создания, журнал ориентировался на высокие научные и этические стандарта и сегодня является одним из ведущих политологических журналов России.

Цель журнала - способствовать научному обмену и сотрудничеству между российскими и зарубежными политологами.

Журнал предназначен для публикации результатов фундаментальных и прикладных научных исследований. Тематическая направленность журнала отражается в следующих постоянных рубриках: «История и философия политики», «Политические институты, процессы и технологии», «Политическая регионалистика и этнополитика», «Политическая культура и идеологии», «Политические проблемы международных отношений и глобализации».

Формат публикаций: научные статьи, обзорные научные материалы, материалы круглых столов, научные рецензии, научные сообщения, посвященные исследовательским проблемам в сфере политики и политологии.

В своей деятельности редакционный совет и редколлегия журнала руководствуется принципами, определяемыми ВАК России для научных журналов, в том числе: наличие института рецензирования для экспертной оценки качества научных статей; информационная открытость издания; наличие и соблюдение правил и этических стандартов представления рукописей авторами

Целевой аудиторией журнала являются российские и зарубежные специалисты-политологи, а также аспиранты и магистры, обучающиеся по направлениям политология, государственное и муниципальное управление и международные отношения.

Журнал строго придерживается международных стандартов публикационной этики, обозначенных в документе СОРЕ (Committee on Publication Ethics) http://publicationethics.org

Полные сведения о журнале и его редакционной политике, требования о подготовке и публикации статей, архив (выпуски с 2011 года) и дополнительная информация размещена на сайте: http://voprospolitolog.ru

Электронный адрес: voprospolitolog@yandex.ru

ISSN 2225-8922 (print)

12 issues a year plus 4 issues a year of the translated (eng.) version Languages: Russian and English http://voprospolitolog

Included in the list of peer-reviewed scientific publications of the Higher Attestation Commission of the Russian Federation Included in the Ulrich's Periodicals Directory Materials of the journal are placed on the RSCI platform of the Russian scientific electronic library - Electronic Journals Library Cyberleninka Subscription index of the journal in the Rospechat Agency catalogue is: 70035

\section{Objectives and themes}

Academic journal "Political Science Issues" is an international peer-reviewed scientific periodical in the field of political studies. The journal has an international character because of the composition of its Editorial Board, its editors, its contributing authors and topics of its publications.

The scientific journal is published since 2011 at the "Publishing House "Science Today". Translated (eng.) version of the journal is published since 2016. Since its inception, the journal was guided by high scientific and ethical standards and today it is one of the leading political science journals in Russia.

The purpose of the journal is to promote scientific exchange and cooperation between Russian and foreign political scientists.

The journal is intended for the publication of the results of fundamental and applied scientific research. Thematic focus of the journal is reflected in the following permanent headings: "History and philosophy of politics," "Political institutions, processes and technologies," "Political regionalism and ethno-politics," "Political culture and ideologies," "Political problems of international relations and globalization."

Format of publications: scientific articles, reviews, scientific materials, materials of round tables, scientific reviews, scientific reports devoted to research problems in the field of politics and political science.

The Editorial Board and the editors of the journal in their activities are guided by the principles defined by VAK of Russia for scientific journals, including: presence of the institute of peer review for the expert quality assessment of scientific articles; information openness of the publications; availability and compliance with the rules and ethical standards for the submission of manuscripts by the authors.

The target audience of the journal is Russian and foreign specialists-political scientists, as well as graduate students and masters in the fields of political science, state and municipal management and international relations.

The journal strictly adheres to the international publishing standards and publication ethics identified in the COPE (Committee on Publication Ethics) document. http://publicationethics.org.

Full details of the journal and its editorial policy, requirements to the preparation and publication of articles, archive (issues since

2011) and additional information are available on the website: http://voprospolitolog.ru

E-mail address: voprospolitolog@yandex.ru 


\section{ИСТОРИЯ И ТЕОРИЯ ПОЛИТИКИ}

Йозеф Храбина. The Problem of Stability

and Durability of Multipolar Structures/Проблема устойчивости

и надежности многополярных структур.

Добромыслов А.С. Демографические исследования

в рамках политической науки .

\section{ПОЛИТИЧЕСКАЯ ИСТОРИЯ РОССИИ}

Чемшит А.А., Стаценко О.С., Чемшит Д.А. О цивилизационной гордости великороссов

\section{ПОЛИТИЧЕСКАЯ СОЦИОЛОГИЯ}

Чимирис E.C. Использование методики анализа фреймов

для изучения доверия: опыт построения исследовательской модели..

Федотова В.A. Идентичность как детерминанта

доверия к власти и политической активности

на примере российской молодежи.

\section{ПОЛИТИЧЕСКИЕ ИНСТИТУТЫ, ПРОЦЕССЫ И ТЕХНОЛОГИИ}

Зимин В.A. Мигранты на российском рынке труда ……………………………………...56

Малахов A.A. Борьба с бедностью как этическая проблема

и политическая стратегия

Внук В.K. Сравнительный анализ предвыборных программ

парламентских политических партий на выборах

в Государственную Думу ФС РФ VIII созыва

Золотарев Н.А., Попов С.И., Гришин В.О. Миграционные процессы

как глобальное социально-политическое явление.

ГОСУДАРСТВЕННОЕ УПРАВЛЕНИЕ И ОТРАСЛЕВЫЕ ПОЛИТИКИ

Гончарова И.В. Устойчивое развитие государства

и социальные технологии.

Чижевский Я.А. К вопросу о внедрении модели

ценностно-ориентированного здравоохранения в России

ТЕОРИЯ И ИСТОРИЯ МЕЖДУНАРОДНЫХ ОТНОШЕНИЙ И ВНЕШНЕЙ ПОЛИТИКИ

Михайленко А.Н., Храмова А.В. Потенциал развития

Евразийского экономического союза

Сурма И.В. Североатлантический альянс

и угрозы цифровому суверенитету России .

Титов В.Б., Макаров А.В. Комплексные подходы

России к формированию образовательного пространства

в геополитическом измерении. 
Тушков А.А., Алехина А.П. Этико-философские учения как паттерн формирования культурной идентичности Китая

Бобров А.К. Циклы российско-американских отношений в постбиполярный период (1991-2021 гг.).

Шангараев Р.Н. Перспективы российско-турецких отношений в контексте строительства канала «Стамбул» и напряженности в Черноморском регионе.

$\boldsymbol{B a \phi u н ~ A . M . ~ И д е о л о г и я ~ г о с у д а р с т в е н н о г о ~ с л у ж е н и я ~ в ~ Я п о н и и ~}$

Васеиова Е.С., Фатхуллина Д.В. «Мягкая сила»

во внешней политике Объединенных Арабских Эмиратов

Кичаев П.А., Малик Е.Н. Политическая система Афганистана

в новой архитектуре международных отношений

Осташова Я.В. Инструменты мягкой силы высшего образования

России в контексте сотрудничества с Казахстаном

Телегин Д.С. Теоретические основы политики

Соединенных Штатов Америки по сдерживанию

Китайской Народной Республики в Индо-Тихоокеанском регионе

Бозоян T.P. Особенности политики АСЕАН

в вопросе трудовой миграции

Аржанов И.А. Международно-правовой статус Арктики

как элемент регионального геополитического соперничества

Власенко К.А. Сравнительный анализ

санкционных политик ЕС и США .............................................................................237

Гао Дай. Вейбо как инструмент общественного надзора в Китае .............................244

Финкельзон С.С. Реакция израильских харедим

на борьбу с пандемией COVID-19 в стране.

У Яньбинь. Основа геополитической концепции

«Индо-Тихоокеанского региона»

Санжиева А.Д. Агентство цифровизации Японии

как актор цифровой трансформации государства

Басов О.Н. Инструменты внутриэлитной борьбы

за политическую власть и влияние с участием

некоммерческих организаций (на примере современных США)

Хазели Реза. Международная трудовая миграция

и трансферты мигрантов

Баракат Кайс Абдулла Махмуд, Сеифи Мустафа Салеем Мустафа,

Абахра Мушир Ибрагим Хасан. Палестино-израильский конфликт

в контексте внешней политики России

\section{СТУДЕНЧЕСКАЯ НАУКА}

Тарасочкина Д.Д., Степанькова Д.С., Зряева Е.С. Дискурс-анализ в исследовании СМИ на примере прессы

в странах Северо-Восточной Азии. 
Баранова Ю.В., Леонова А.А., Фам Тхи Минь Хуен. Проблемы международно-правового регулирования предотвращения загрязнения морской среды в Северной Пацифике

Кражан A.C. Актуальность введения антикоррупционного комплаенс-контроля в российский бизнес.

Дубинин А.А. Терроризм в Сахельском регионе:

опыт Франции и новые вызовы 327

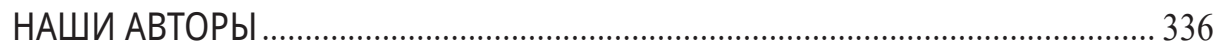

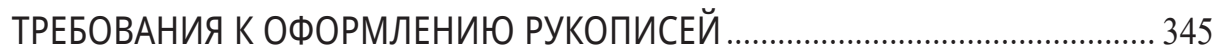

РЕДАКЦИОННЫЙ СОВЕТ 347 


\title{
АГЕНТСТВО ЦИФРОВИЗАЦИИ ЯПОНИИ КАК АКТОР ЦИФРОВОЙ ТРАНСФОРМАЦИИ ГОСУДАРСТВА
}

\begin{abstract}
Данная статья рассматривает деятельность Агентства циифровизациии - нового исполнительного органа японского правительства, созданного в сентябре 2021 года. Анализ деятельности Агентства позволяет проследить тенденции сочиально-экономического и политического развития японского общества, выделить изменения в государственном управлении и строить прогнозы относительно внутренней и внешней политики страны. Предмет исследования - политика Агентства, направленная на маситабную ичифровизацию японского государства. Изучение данного аспекта представляет собой большое научное и практическое значение, так как Агентство берет на себя основную ответственность за успешное проведение ичифровизациии.
\end{abstract}

Ключевые слова: цифрровизачия, Япония, политический процесс, информационная безопасность, ијифровая трансформачия, Агентство иџифровизаиии, дигитализация общества.

С 1 сентября 2021 года начало функционировать Агентство цифровизации, которое можно назвать главным штабом по разработке цифровой стратегии японского государства. Агентство призвано создать план внедрения высоких технологий и достижений технического и технологического развития во все области жизни японских граждан, включая административные услуги, медицину, образование.

До сих пор министерства и правительственные агентства создавали нормативные и регулирующие системы отдельно друг от друга, что значительно затрудняло получение государственными служащими информации о системах других министерств или ведомств или даже о системах другого подразделения в их собственной организации. В результате ведомства не были способны предоставить гражданам удобный доступ к административным услугам. Часто пользователям правительственных сайтов приходится возвращаться к результатам поиска снова и снова в попытках получить услуги, 
заново вводить необходимую для ее получения личную информацию несколько раз, что в конечном счете вынуждает лично посетить административный орган.

Деятельность Агентства цифровизации, которое начало функционировать менее полугода назад, представляет собой актуальную проблему, мало исследованную не только в российском научном поле, но и за рубежом. Основой нашего исследования выступили статьи японских ученых, материалы и отчеты, опубликованные министерствами японского правительства, а также электронные ресурсы Агентства цифровизации Японии.

Задачи нашего исследования заключаются в определении роли, стратегии и первых реальных шагов Агентства цифровизации Японии как актора цифровой трансформации государства.

Создание Агентства - важнейшая часть глобальной программы цифровой трансформации, которая является приоритетным направлением внутренней политики страны, обозначенным предыдущим премьер-министром Ёсихидэ Суга. Он признал, что Япония испытывает трудности во внедрении высоких технологий в процесс государственного управления и предоставления административных услуг населению. Несмотря на то, что страна является традиционным центром инноваций и многочисленных технологических компаний, по итогам опроса The Economist, проведенного в 30 странах Организацией экономического сотрудничества и развития, Япония оказалась на последнем месте по предоставлению цифровых услуг. В 2018 году менее $10 \%$ японцев запрашивали что-либо у правительства онлайн (по сравнению с 80\% граждан Исландии). Япония отстает даже от стран, считающихся технологически отсталыми, таких как, например, Мексика [9]. Помимо этого, 88,3\% японских организаций пользуются ИТ-продуктами, разработанными другими («посторонними») компаниями. Для сравнения, в США лишь 33,8\% ИТ-систем разрабатываются аутсорсинговыми компаниями [10]. Внедрение облачного программного обеспечения составляет менее 20\% в Японии, отставая от многих других стран, где этот показатель превышает 40\% [9].

Пандемия COVID-19 ярче продемонстрировала задержку цифрового развития в Японии. Например, при получении финансовой помощи, направленной на заведения общественного питания, которые подчинились требованиям правительства о закрытии, рестораторы столкнулись с длительным ожиданием пособий, поскольку необходимые документы, подтверждающие приостановку работы, оформлялись в бумажном формате и требовали большого количества времени для проведения детальной проверки. Программа экстренной материальной поддержки населения в размере 100000 иен на человека (920 долларов) также застопорилась в связи с тем, что заявки на получение пособий обрабатывались вручную [8]. Слабые ИТ-системы в больницах и школах препятствовали своевременному предоставлению 
услуг телемедицины и проведению онлайн-уроков в период изоляции. Для скорейшего выхода из цифрового тупика и было основано Агентство цифровизации.

Нормативно-правовой базой работы нового органа являются Основной закон о формировании цифрового общества и Основной закон об учреждении Агентства цифровизации. В соответствии с текстом документов, в компетенции Агентства входит:

- планирование и комплексная координация основных мер по реализации цифрового общества;

- планирование базовой политики в отношении внедрения индивидуальных идентификационных номеров граждан, включая программу «Мой номер»;

- разработка основных принципов проверки личности с использованием информационно-коммуникационных технологий;

- разработка методов электронного подтверждения коммерческой регистрации;

- планирование политики стандартизации данных;

- разработка и продвижение базовых методов по созданию и управлению информационными системами национальных, местных общественных организаций и частного бизнеса квазигосударственного сектора;

- надзор за созданием правительственных информационных систем и их управлением, общее бюджетирование [3].

Согласно официальному сайту организации, она стремится выступать в качестве «командной башни» для формирования цифрового общества, которое охватит всех граждан, продвигает ориентированную на будущее цифровую трансформацию и прикладывает усилия на благо строительства государственно-частной инфраструктуры в ближайшие пять лет [5].

Следует отметить, что теперь правительство воспринимается как стартап по предоставлению услуг, который функционирует на основе высоко мотивированного сотрудничества государства, местных органов власти и частных предприятий.

Итак, основной целью Агентства является устранение цифровой разрозненности в административных системах. Ведомство нацелено на значительное качественно-временное улучшение передачи данных между отдельными государственными организациями, что приведет к повышению эффективности их услуг и операций. Оно также ориентировано на использование опыта частного сектора и активное трудоустройство специалистов из негосударственных компаний, что должно обеспечить более гибкий и быстрый подход к решению задач и внедрению новшеств.

Определены основные принципы работы Агентства на пути к реализации цифрового общества, среди них открытость и прозрачность, справедливость и этика, безопасность, преемственность, стабильность и надежность, 
скорость и гибкость, инклюзивность и разнообразие, технологический прорыв и вклад в международное сотрудничество.

Структура ведомства представляет собой четко организованную систему. Руководящие посты распределены следующим образом: премьер-министр, министр цифровизации (Карэн Макисима), заместитель министра цифровизации (Фумиаки Кобаяси) и вице-министр по цифровизации (Таро Ямада), директор по цифровым технологиям (Ёко Исикура), заместитель директора по цифровым технологиям (Коити Акаиси). У руководства есть три высокопоставленных советника. Также в Агентстве назначены должности главного архитектора, главного конструктора, директора по информационной безопасности, директора по продукту и главного технического директора. Всего в организации 4 крупные рабочие группы: стратегическая, группа по совместному функционированию цифрового общества, группа по услугам для населения, и группа по обслуживанию министерств и ведомств. У каждой группы есть глава и его заместитель, а также внутреннее разделение по командам, сферам деятельности и департаментам. В целом, в Агентстве разрабатываются такие области, как управление государственным облачным хранилищем данных, планирование стратегии международного сотрудничества, управление цифровым образованием и здравоохранением, региональной цифровой инфраструктурой, ресурсами.

Отбор сотрудников проводился в четыре этапа с января по июль 2021 года среди специалистов из частного сектора. Описание позиций и содержание работы были четко и подробно определены, что было беспрецедентной инициативой для традиционного найма в центральные правительственные учреждения. В результате на должность менеджера по проектам, которая предполагает 35 мест, было подано 1432 заявки; на позицию специалиста по безопасности претендовали 469 человек при наборе 43; 336 кандидатов подали свои резюме на вакансию сотрудников высшего звена (из них было отобрано 10 человек); на позиции 40 продакт-менеджеров было 450 кандидатов. Из 600 новых сотрудников 250 были наняты из частных компаний [11].

Они будут трудиться над следующими задачами, которые ставит перед собой ведомство:

1. Обеспечение безопасного, стабильного и высокоэффективного предоставления административных услуг. Для этого планируется улучшить систему «Мой номер» - систему личных индивидуальных номеров. Такой номер присваивается каждому жителю Японии, в том числе иностранным студентам, и используется для прохождения необходимых административных процедур. Для юридических лиц предусмотрено нечто схожее GBizID, то есть правительственный идентификатор для бизнеса. Он позволит проходить административные процедуры без лишних документов в онлайн-формате. 
2. Создание правительственной информационной системы, которой могут пользоваться государственные чиновники и работники муниципалитетов.

3. Повышение уровня кибербезопасности страны.

4. Приведение к единому стандарту правительственных интернет-порталов, а также повышение их доступности так, чтобы люди всех возрастных и иных категорий были способны ими уверенно пользоваться.

5. Реализация проекта OneStop, объединяющего большинство административных услуг в одном месте онлайн (воспитание детей, переезд, регистрация смерти, наследование, социальное страхование, налогообложения, иммиграционные процедуры и т.д.).

6. Подготовка ИТ-специалистов.

Планируется, что будут оцифрованы и стандартизированы процедуры в 31 административном подразделении. Первым крупным проектом агентства стал запуск мобильного приложения для регистрации вакцинации от новой коронавирусной инфекции в конце декабря 2021 года. Приложение можно использовать для издания электронного сертификата о вакцинации для внутренних и заграничных поездок, загрузив его на смартфон на платформе Android или IOS. По сообщениям CMИ, в первый же день в разных частях страны выявили несколько случаев некорректной работы приложения. По результатам проверки, выяснилось, что ошибки возникали из-за большого пользовательского ажиотажа, который вызвал перегрузку серверов. Спустя несколько часов работа программы возобновилась в штатном режиме [1].

Мы изучили большое количество отзывов о приложении, опубликованных в App Store и Google Play Store - магазинах приложений для смартфонов на платформах IOS и Android. Средняя оценка, которую пользователи дают программе, -3.7 из 5. Многие комментарии содержат критику. В частности, люди недовольны тем, что приложение поддерживает только японский язык, вследствие иностранные граждане, прошедшие вакцинацию на территории Японии и не владеющие японским языком, не могут им воспользоваться без посторонней помощи. В некоторых случаях сканер программы не распознает символы в именах и номерах паспортов, что ведет к неверной регистрации. У владельцев непопулярных моделей смартфонов не получалось воспользоваться приложением. Среди отрицательных отзывов присутствуют положительные, в которых люди отмечают удобство получения электронного сертификата онлайн с использованием личного гаджета. На 9 января 2022 года число выпущенных посредством приложения сертификатов составило 2734228 [4].

Способность Агентства цифровизации эффективно координировать деятельность разных министерств и ведомств, реализовывать политику формирования цифрового общества и способствовать цифровой трансфор- 
мации государства, вероятно, будет проверена в самое ближайшее время, поскольку Япония продолжает бороться с пандемией, что создает необходимость скорейшего решения вопросов технологического отставания страны и недостаточного использования средств дигитализации.

\section{БИБЛИОГРАФИЧЕСКИЙ СПИСОК:}

1. Многочисленные ошибки в государственном приложении о вакцинации // NHK // https://www3.nhk.or.jp/news/html/20211220/k10013396511000. html.

2. Основной закон об учреждении Агентства цифровизации // https:// elaws.e-gov.go.jp/document?lawid=503AC0000000036.

3. Основной закон об учреждении Агентства цифровизации // https:// elaws.e-gov.go.jp/document?lawid=503AC0000000036.

4. Отчет о числе изданных электронных сертификатов вакцинации // Агентство цифровизации Японии // https://www.digital.go.jp/policies/posts/vaccinecert.

5. Официальный портал Агентства цифровизации Японии // https://www. digital.go.jp/.

6. Официальный сайт магазина приложений App Store // https://apps. apple.com/jp/app/AA/id1593815264\#see-all/reviews.

7. Официальный сайт магазина приложений Google Play Store // https:// play.google.com/store/apps/details?id=jp.go.digital.vrs.vpa\&hl=ja\&gl=US\&sho wAllReviews $=$ true.

8. Japan passes laws to set up digital policy agency in September // Nikkei Asia// https://asia.nikkei.com/Politics/Japan-passes-laws-to-set-up-digital-policyagency-in-September.

9. Kannan J. The Digitalization of Japan // William Blair // https://active. williamblair.com/global-equity/jayeshkannan/the-digitalization-of-japan/\#close.

10. Nhu Le. The relevance of IT cost management and transformation // Strategy\& (PwC) // https://www.strategyand.pwc.com/it/en/insights/2021/itcost-transformation.html.

11. Tsuwaki Y. Использование человеческих ресурсов из частного сектора и организационная структура Агентства цифровизации // Project Design Online // https:/www.projectdesign.jp/articles/4a49b8c8-3dce-47ac-a869-bf9404f2b335. 
A.D. SANZHIEVA

Postgraduate student of ISAA

Moscow State University M.V. Lomonosov,

Moscow, Russia

\section{THE DIGITAL AGENCY OF JAPAN AS AN ACTOR OF THE DIGITAL TRANSFORMATION OF THE STATE}

The article examines the activities of the Digital Agency, a new executive body of the Japanese government, established in September 2021. The analysis of the Agency's work makes it possible to trace the trends in the socio-economic and political development of Japanese society, highlight changes in public administration and make forecasts regarding the country's domestic and foreign policy. The subject of the study is the Agency's policy aimed at large-scale digitalization of the Japanese state. The study of this aspect is of great scientific and practical importance, since the Agency assumes the main responsibility for the successful implementation of digitalization.

Key words: digitalization, Japan, political process, information security, digital transformation, Digitalization Agency, digitalization of society. 